$\xi_{p}$

\title{
Short Note on Topological Fuzzy Spaces of the Behaviour of GS $\square$ fuzzy Closed Sets
}

\author{
M. Mary Victoria Florence ${ }^{1}$, E.Priyadarshini ${ }^{2}$,M.Vidhya ${ }^{3}$, A.Govindarajan $^{4}$,E.P.Siva ${ }^{5}$ \\ ${ }^{I}$ Jeppiaar Maamallan Engineering College, \\ ${ }^{2,3}$ Sathyabama Institute of Science And Technology \\ ${ }^{4,5}$ SRM Institute of Science and Technology, \\ *Corresponding author E-mail: priyaeb@gmail.com
}

\begin{abstract}
Many fuzzy topologists have very good interest in generalized fuzzy closed sets and in fuzzy point set topology. Here, properties of GS $\square$ in fuzzy topological spaces and its relationship with other generalized fuzzy closed sets has been discussed.
\end{abstract}

Keywords: closed sets; fuzzy; kernel; open sets ; topological spaces;

\section{Introduction}

In General Fuzzy Topology, generalized fuzzy open sets play a vital role the recent research topics worldwide. Semi open sets was defined by Levine [1] as weaker sets than open sets in topological spaces. After Levine's semi open set, Mathematicians written papers on new open and generalized open sets. As the continuation of the work by Levine on generalized closed sets. Maki [2] discussed about GS sets in the above domain. The GS set is said to be the saturated set which is equal to its kernel. Arenas [3] introduced the notation of $\square$-open and $\square$-closed sets. The notions of $\square$-frontier , $\square \square$-exterior , $\square$-derived, $\square$-border was introduced by Miguel Caldas et.al[4] and it was proved that their properties are analogous to open sets properties along with $\square$-closure operator. $\square$ generalized closed sets $(\square \mathrm{g}, \square-\mathrm{g}, \mathrm{g} \square)$ properties were introduced by Caldas, S. Jafari and T. Noiri [5]. The $\square$ g open and closed sets are weaker than open and closed sets of fuzzy topology and are stronger than the generalized open and closed sets.

A class of fuzzy called GS $\square$ fuzzy which is closed in fuzzy topological domain is discussed in this paper along with some properties. It was proved that GS $\square$ fuzzy closed sets are weaker than $\square$-fuzzy open and closed sets but stronger than GS $\square$ fuzzy closure sets, GS $\square$ fuzzy open sets. But at the same time, fuzzy topological space will not be formed by GS $\square$ fuzzy closure sets since the U of GS $\square$ fuzzy closure sets is not GS $\square$ fuzzy closure sets. These notations (X, $\square \square$ ), (Y, $\square \square$ ) and (Z, $\square \square$ ) will indicate fuzzy topological spaces without any separation axioms.

\section{Basic Terminologies}

\section{Definition 2.1:}

$\alpha$ is contained in $\operatorname{CL}(\operatorname{INT}(\alpha))$, hence the set $\alpha$ is defined as semi fuzzy open set . $\alpha$ is contained in $\operatorname{INT}(\mathrm{CL}(\alpha))$, hence the set $\alpha$ is defined as pre fuzzy open set.

$\alpha=\operatorname{INT}(\mathrm{CL}(\alpha))$ hence the set $\alpha$ is defined as regular fuzzy open set.The complementary sets of pre, semi and regular fuzzy open are called Semi closed sets. p(CL $(\alpha))$ is the joint of fuzzy partially closed sets having $\alpha$.

Definition 2.2 : Fuzzy topological space is defined in the following manner

1. $\mathrm{CL}(\alpha)$ is contained in $\square \mathrm{U}$ where $\mathrm{U}$ is open in $\mathrm{Y}$,hence $\alpha$ is said to be generalized closed .

2. $\mathrm{CL}(\alpha)$ is contained in $\mathrm{U}$ where $\mathrm{U}$ is g-open in $\mathrm{Y}$,hence $\alpha$ is said to be fuzzy $\mathrm{g} *$ closure set .

3. $\mathrm{S}[\mathrm{CL}(\alpha)]$ is contained in $\square \mathrm{U} \square$, hence $\mathrm{U}$ is semi open set of $\mathrm{Y}$ it is said to be generalized fuzzy semi closed set .

4. Fuzzy pre closure if P $[C L(\alpha)] \square$ is contained in U, whenever $\alpha \square \square \mathrm{U}$ and $\mathrm{U}$ is fuzzy open in Y.

5. Fuzzy semi closure if S CL $(\alpha)$ is contained in $U$, when-ever $\alpha \square \mathrm{U}$ and $\mathrm{U}$ is fuzzy open set of $\mathrm{Y}$.

6. If $\alpha$ is the intersection of $\beta$ and $\gamma, \beta$ being a $\square$--set, $\gamma$ being a closed fuzzy set, then $\alpha$ is said to be fuzzy $\square$-closure .

7. $\mathrm{CL}(\alpha) \square \square$ is contained in $\mathrm{U}$ and $\alpha \square \mathrm{U}, \alpha$ of $\mathrm{Y}$ is defined as fuzzy $\square$ - GS closure set .

These complementary closed sets are said to be its respective fuzzy open sets. $\square$, which is a closed subset $\alpha$ of $\mathrm{X}$ is denoted by $\operatorname{CL}(\square(\alpha)),(\operatorname{CL}(\alpha))$ is the combination of all $\square$ closed sets containing $\alpha$.

Proposition 2.3: If $S$ is contained in a fuzzy topology $X$, then

If $\square$ - fuzzy closure is $\mathrm{S}$ and $\mathrm{S}=\mathrm{T} \square \mathrm{CL}(\mathrm{S}), \mathrm{S}=\mathrm{S} \quad \square \mathrm{CL} \alpha(\mathrm{S})$, where $\mathrm{T}$ is a $\square$-fuzzy set.

Lemma 2.4: Let $\mathrm{S}$ and $\mathrm{T}$ be subsets of a fuzzy topological domain. 1. $\mathrm{S}$ being fuzzy closed in $\square \square \mathrm{S}$ is $\mathrm{CL}(\square(\mathrm{S})$ ). 
2. $\quad \mathrm{CL}(\square(\mathrm{S}))=\square\{\mathrm{F} \square \square \square \square \mathrm{CL}(\mathrm{X}, \square \square) / \mathrm{S} \square \mathrm{F}\}$

3. $\mathrm{S} \square \mathrm{CL}(\square$ (S) $\square \square \square \mathrm{CL}(\mathrm{S})$.

4. If $\mathrm{S} \square \square \mathrm{T}$, then $\mathrm{CL}(\square$ (S) $\square \square \square$ is a subset of $\square \square \square \square \square \square \square(\mathrm{T})$.

5. $\mathrm{CL}(\square$ (S) ) is $\square$-fuzzy closed.

6. The largest $\square$ fuzzy open set is $\square$ (S) contained in $S$.

7. In case of $\mathrm{S}$ being fuzzy open in $\square \square \square$ then $\mathrm{S}=\mathrm{INT} \square$ (S).

8. $\quad \mathrm{X} \backslash \mathrm{INT} \square(\mathrm{S})=\mathrm{CL}(\square(\mathrm{X} \mid \mathrm{S}))$

Proposition 2.5: $\alpha$ being a fuzzy subset of a topological domain X. $\square$-fuzzy limit point of $\square \square \square \mathrm{X} \square(\alpha \backslash\{\square\})=\square \square \square$ The $\square$ fuzzy set of $\alpha$ contains the set all limit points of $\alpha$ that are $\square$ fuzzy denoted as $\mathrm{D} \square \alpha$.

Lemma 2.6: The statements which are given below are true

1. $\mathrm{CL}(\square(\alpha))=\alpha \square \square \square \square \mathrm{R} \square \alpha$.

2. $\mathrm{R} \square \alpha$ is a subset of $(\alpha)$.

3. $\alpha$ is a subset of $\beta$ then $R \square \alpha$ is a subset of $R \square \beta$.

4. $\mathrm{R} \square \alpha$ is a subset of $\mathrm{R} \square \square \beta \square \mathrm{R} \square(\alpha \square \beta)$ and

5. $\mathrm{R} \square(\alpha \square \square \beta)$ is a subset of $\mathrm{R} \square \alpha$ intersection of $\mathrm{R} \square \beta$.

6. INT $\square \square \square \quad(\alpha)$ ] $\square \quad$ [INT $\square \square$ ( $\beta$ ) ] $\square \square$ INT $\square \square \square \square$ $(\alpha \square \beta)]$.

7. $\quad$ INT $\square \square \square \square \quad(\alpha) \square \square \quad$ INT $\square \square \square \square \quad(\beta)]$ INT $\square \square \square \square(\alpha \square \beta)]$.

8. $\quad$ INT $\square \square \square \square(\alpha)]=\alpha \backslash \mathrm{R} \square(\mathrm{X} \backslash \alpha)$

\section{Some properties of GS $\square \square \square$ fuzzy closure sets}

Proposition 3.1: (Y, $\square \Omega$ ) be a fuzzy topological domain . If $\mathrm{CL}(\square$ ( $(\alpha)) \square \square \square \square \square$, whenever $\alpha \square \square \square$, where $\square$ is semi open in Y. A subset $\alpha$ of Y is said to be a GS $\square$ fuzzy closure set. First we prove GS $\square$ fuzzy closure sets are weaker than $\square$-fuzzy closure sets and fuzzy closed sets but stronger than GS $\square$ fuzzy closed sets.

Theorem 3.2: Each and every $\square$-fuzzy closure is GS $\square$ fuzzy closure.

Proof : If $\mathrm{T} \square \square$, T is $\square$ closure set, then CL(T) is equal to T which is a subset of U. Hence T is GS $\square$ fuzzy closure.

Theorem 3.3: $\mathrm{T}$ is a semi open fuzzy subset of $(\mathrm{Y}, \Omega)$ Hence $\mathrm{T}$ is a GS $\square$ fuzzy closure since $T$ is $\square$ fuzzy closure set.

Proof : Here $\alpha$ is GS $\square$ fuzzy closed and fuzzy semi open. Since $\alpha$ is GS $\square$ fuzzy closed and CL $\square \square \square(\alpha)] \square \square$ is contained in $\alpha$. Hence $\alpha$ is $\square \square$ fuzzy closed.

Theorem 3.4: All open fuzzy set is GS $\square$ closed in fuzzy.

Proof : Since all open set in fuzzy is $\square \square$ closed and all $\square$ fuzzy closure set is GS $\square$ fuzzy closure set, we have all open set in fuzzy to be GS $\square$ closed fuzzy.

Theorem 3.5: All GS $\square \square$ closed set in fuzzy is GS $\square$ closed set in fuzzy of the space $(Y, \square \gamma)$.
Proof : If T is GS $\square \square$ fuzzy closure in (Y, $\square \gamma$ ), $\alpha$ is contained in $\square \lambda$ with $\lambda$ is fuzzy open set in (Y, $\square \gamma)$. Since every fuzzy open set is fuzzy semi open and $\alpha$ is GS $\square$ fuzzy closed, we have $\mathrm{CL}(\square(\alpha)) \square \square \square \square \lambda$. Hence $\alpha$ is GS $\square$ fuzzy closed set.

Theorem 3.6: Each and every $\square$ closure set is said to be GS $\square$ fuzzy closed set in (Y, $\square \gamma)$.

Proof : $\alpha$ being $\square$ closed set in (Y, $\square \gamma$ ).and $\alpha$ is a subset of $\lambda$, where $\lambda$ is fuzzy semi open set in (Y, $\square \gamma$ ).As $\alpha$ is $\square$ fuzzy closed, we have $\operatorname{CL}(\mathrm{A}) \square$ is a subset of $\lambda$. Hence we have $\mathrm{CL}(\alpha) \square \square \square \square \lambda \square \square$. Thus $\alpha$ is GS $\square \square$ fuzzy closed set.

\section{References}

[1] N.Levine, "Semi-open Sets and Semi Continuity in Topological Spaces", Amer.Math.Monthly, 70, (1963), 6-41.

[2] H.Maki, "Generalized $\square$-sets and the Associated Closure Operator", The Special Issue inCommemoration of Prof. Kazusada IKEDS Retirement, 1, Oct (1986), 139-146.

[3] Francisco G. Arenas, Julian Dontchev and Maxmillaian Ganster, "On $\square$-sets and the Dual of Generalized Continuity". Question Answers GEN. Topology, 15, (1997) 3-13.

[4] M. Caldas, S.Jafari and T.Noiri, “On $\square$-generalised Closed Sets in Topological Spaces"Acta Math. Hungar, 118(4), (2008), 337-343.

[5] M. Caldas, and Jafari, S, "On Some Low Separation Axioms Via $\square$ Open and $\square$ Closure Operator". Rend. Circ.Mat.Di.Palermo, 54(2), (2005) 195-208 